\title{
Overexpression of full-length and partial DREB2A enhances soybean drought tolerance
}

\begin{abstract}
Juliane Prela Marinho ${ }^{1,2}{ }^{-}$, Renata Fuganti Pagliarini2 ${ }^{(D}$, Mayla Daiane Correa Molinari ${ }^{2} \mathbb{D}$, Juliana Marcolino-Gomes ${ }^{2} \mathbb{D}$, André Luís Hartmann Caranhoto $^{2}$, Silvana Regina Rockenbach Marin ${ }^{2}$, Maria Cristina Neves de Oliveira ${ }^{2} \mathbb{D}$, José Salvador Simoneti Foloni ${ }^{2}$, Carlos Lasaro Pereira de

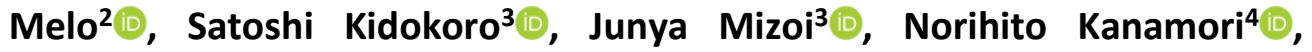
Kazuko Yamaguchi-Shinozaki ${ }^{3,5}{ }^{-}$, Kazuo Nakashima ${ }^{4}$, Alexandre Lima Nepomuceno2 ${ }^{2}$ and Liliane Marcia Mertz-Henning ${ }^{2, *}$
\end{abstract}

\begin{abstract}
${ }^{1}$ General Biology Department, Londrina State University. Londrina, PR, Brazil. ${ }^{2}$ Embrapa Soybean, Carlos João Strass Road, Orlando Amaral Acess, Warta., Londrina, PR, Brazil, CEP 86001-970. ${ }^{3}$ Laboratory of Plant Molecular Physiology, The University of Tokyo, Bunkyo-ku, Tokyo, Japan. ${ }^{4}$ Japan International Research Center for Agricultural Sciences, Tsukuba, Ibaraki, Japan. ${ }^{5}$ Research Institute for Agricultural and Life Sciences, Tokyo University of Agriculture, Setagaya-ku, Tokyo, Japan. *Corresponding author, E-mail: liliane.henning@embrapa.br
\end{abstract}

\section{ABSTRACT}

Soybean is an important commodity worldwide. Abiotic conditions can adversely disturb crop growth and final yield. The transcription factor DehydrationResponsive Element-Binding Proteins 2 (DREB2) acts as a regulator of drought responses. This study aimed to characterize soybean plants genetically modified with GmDREB2A;2 FL and GmDREB2A;2 CA for molecular, physiological, and agronomic responses, at different growing periods. Results showed that seedlings from GmDREB2A;2 FL event presented lower growth reduction under osmotic treatment during germination. The GmDREB2A;2 FL and GmDREB2A;2 CA events showed improved performance in experiments of water deficit imposed in the vegetative period and higher rates in physiological parameters. In the reproductive period, there was a trend of higher yield compounds in GM GmDREB2A;2 FL event when compared to other genotypes and treatments. GmDREB2A;2 FL event presented superior performance due to the higher expression levels of the cisgene and drought-induced genes.

Keywords: Glycine max, genetically modified plants, heat tolerance, activating responses to drought, silencing responses to drought, controlling responses to drought.

Copyright: ( 2022 Agronomy Science and Biotechnology. This is an open access article distributed under the terms of the Creative Commons Attribution License, which permits unrestricted use, distribution, and reproduction in any medium, since the original author and source are credited. 


\section{INTRODUCTION}

Soybean growth, development, and final yield can be greatly impaired by abiotic stresses. Seeking alternatives to minimize these damages, scientists are developing plants more tolerant to water deficit and heat, by introducing responsive genes as transcription factors (TFs) into soybean cultivars (Lopes et al. 2012). The overexpression of a constitutively active (CA) form from DREB2A, which has a negative regulatory domain deletion in Arabidopsis, resulted in improved drought and heat tolerances (Sakuma et al., 2006a; Sakuma et al., 2006b).

Genes homologous to AtDREB2A were identified in crops such as maize (Qin et al. 2007), potato (Guo \& Wang, 2011), rice (Dubouzet et al., 2003), and wheat (Terashima \& Takumi, 2009). In soybean, Mizoi et al. (2013) showed that GmDREB2A;2 was highly induced under drought, heat, and cold. The heterologous expression of this TF in Arabidopsis triggered the induction of drought-responsive genes and enhanced tolerance. These outcomes suggest that plants from different species overexpressing AtDREB2A and DREB2A-like proteins have shown improvement in tolerance to drought and heat, which can simultaneously happen in field conditions.

However, most of these manuscripts focus on understanding these tolerances in plants growing under greenhouse during the vegetative period, not considering responses in seedling and/or at reproductive phase. The objective of this study was to evaluate drought tolerance in soybean plants transformed with the full length and constitutively active forms of GMDREB2A; 2 in seedling, at vegetative (VEG), and reproductive (REP) phases. Molecular, physiological, growth and, agronomic parameters were examined under control (C), and water deficit (WD) treatment conditions. These understandings can complement information on how TF DREB2A acts in soybean plants activating/silencing and controlling responses to drought in different developmental periods. This knowledge might facilitate the design of alternative strategies to improve WD tolerance in this important commodity crop.

\section{MATERIAL AND METHODS}

\section{Plasmid and soybean transformation}

Two expression cassettes, pCambia3300J-35S:GmDREB2A;2 FL and pCambia3300J-35S:GmDREB2A;2 CA, were introduced separately into $A$. tumefaciens via electroporation. DREB2A; 2 CA (Constitutively Active) form has a deletion (29 bp between protein residues 136 and 165) of a negative regulation domain (NRD); while FL contains the complete coding region without modification (Mizoi et al. 2013). Both genetic constructions were under the control of the constitutive promoter CAMV $35 \mathrm{~S}$ and TNOS terminator. Bar gene was used as a selective agent (Molinari et al. 2018); while NPTII was applied to select the transformed colonies. Conventional cultivar - BRS 283, non-transformed, was used for transformation, performed as described by Paz, Martinez, Kalvig, Fonger and Wang (2006). Survival seedlings from the selection process were transferred to a mixture of substrate (soil:sand:organic compounds 3:2:2):sand (1:1). Positive events to cisgenes were identified through conventional $P C R$ using specific primers (GmDREB2A;2 - Glyma.14G056200, F- TGATGAGTCTGCGTTGATGC, and RTCCCAACAACTTGGCATCTG). After confirmation, these events were kept in the greenhouse, and seeds generation progress was carried out. Four distinct experiments were also conducted as shown below. 


\section{Greenhouse experiment for gene expression analysis and yield components evaluation}

To evaluate responses at the VEG (vegetative) period, an experiment with homozygous plants from the $T_{3}$ generation was conducted in randomized complete block design, under a $4 \times 2$ factorial arrangement (i.e., four soybean genotypes and two water conditions), with 6 biological replicates. The genotypes comprised two GmDREB2A;2 CA events, one GmDREB2A;2 FL event and the cultivar BRS 283. The water conditions were control (C) and water deficit (WD). For germination, seeds were put on Germitest paper for $96 \mathrm{~h}$ at $25 \pm 1^{\circ} \mathrm{C}$ and $100 \%$ relative humidity (RH). Then, single seedlings were moved to $5 \mathrm{~kg}$ pots filled with a 1:1 sand:substrate mixture. All seedlings were grown at $80 \%$ field capacity (FC) in a greenhouse at $28 \pm 2^{\circ} \mathrm{C}$ until plants reached the V3 developmental stage, when WD treatment was imposed, by withholding irrigation. The control group was maintained at $80 \%$ FC. Leaf samples were collected after 10 days to determine relative water content (RWC). A second experiment was performed to evaluate soybean responses during the REP (reproductive) period. WD treatment was imposed when plants were at R1/R2 developmental stages for 10 days. Leaf samples of the third fully expanded trifoliate leaf were collected from both experiments. After the collection, plants were kept under irrigated conditions until the end of the cycle. Yield components (total pod dry weight the total number of pods and seeds, total dry seed weight, and final yield) were determined.

\section{Gene expression analysis through RT-Qpcr}

Total RNA from soybean leaves was extracted Using Trizol $^{\circ}$ reagent and treated with DNAse I kit (Invitrogen). cDNA was synthesized using SuperScript III FirstStrand Synthesis System (Invitrogen), according to the manufacturer's directives. The relative gene expression level of cisgene GmDREB2A;2 (Glyma.14G056200), LEA2 (Glyma.09G185500 F- GGTAGACAGCATTCTAGTGG and RTACCATAGACACCGGTAGT), LEA6 (Glyma.17G164200, FAAAGGCACAGAGTGATGAAT and R- CTTGATGACCTTGTGTACCA), and HSP70 (Glyma.17G072400, F- TTTCGGGTTTGAATGTGTTG and RAGGTCAAAGATAAGCACGTT) genes was carried out in GM events and BRS 283. Gene sequences were uploaded from Phytozome and primers were designed using the Primer3Plus software. The expression normalization was carried out by endogenous control ELF1- 8 (Glyma.13G073200, F- GTTGAAAAGCCAGGGGACA and R- TCTTACCCCTTGAGCGTGG) and FYVE (Glyma.13G114700, FTTCTGTCTTCTGCAAGTGGTG and R- GATCCCTCATCCATACATTTCAG) (MarcolinoGomes et al., 2015). RT-qPCR reactions were carried out in three biologicals replicates (each one composed of bulk of two biological replicates, $n=6$ ), and three technical replicates. Reactions were comprised of cDNAs, $0.2 \mu \mathrm{M} F$ and R primers, and $1 x$ reaction buffer Platinum ${ }^{\circ}$ SYBR Green ${ }^{\circ}$ qPCR SuperMix UDG (Invitrogen). Reactions were made through a $7900 \mathrm{HT}$ thermocycler and cycling parameters used were $50^{\circ} \mathrm{C}$ for $2 \mathrm{~min} ; 95^{\circ} \mathrm{C}$ for $10 \mathrm{~min} ; 40$ cycles of $95^{\circ} \mathrm{C}$ for $15 \mathrm{~s}, 60^{\circ} \mathrm{C}$ for $1 \mathrm{~min}$; $95 \circ \mathrm{C}$ for $15 \mathrm{~s} ; 60^{\circ} \mathrm{C}$ for $15 \mathrm{~s}$, and $95^{\circ} \mathrm{C}$ for $15 \mathrm{~s}$. The expression level was determined according to Livak and Schmittgen (2001). Control plants were used as calibrators to evaluate $L E A 2, L E A 6$, and $H S P 70$ genes and to evaluate the overexpression of $G M D R E B 2 A ; 2$ genes. Calibration was carried out in comparison to the plants of BRS 283, which have the GMDREB2A endogenous gene. 
Relative growth rate (RGR) in seedlings during germination, growth parameters and physiological responses in the VEG period

Germination of seeds from BRS 283 cultivar and GM events was assayed in polyethylene glycol (PEG-8000) in the concentrations of 0.0MPa (control - distilled water) and $-0.2 \mathrm{MPa}\left(118.9 \mathrm{~g} \mathrm{~L}^{-1}\right)$. The experiment was completely randomized, with four replicates (20 seeds each). The seeds were placed in Germitest paper, moistened with water/PEG concentration volume equal to two and a half times dry paper mass, and kept in the germination chamber at $25 \pm 1^{\circ} \mathrm{C}$ and $100 \%$ relative humidity (RH), for $120 \mathrm{~h}$. Total seedling (TSG), hypocotyl (HG), and roots growth $(R G)$ were measured. Using these data, growth reduction rate (GRR) was assayed by comparing plants grown under both treatments, according to Villela and Beckert (2001).

To evaluate growth parameters and physiological responses in the VEG period, seeds were germinated, and seedlings were relocated to $1 \mathrm{~L}$ pots filled with the substrate, each pot containing only one seedling. The experiment was performed in $4 \times 2$ factorial arrangement in a randomized complete block design with 9 replicates, under previously described conditions. At the V3 stage, WD treatment was imposed and plants stomatal conductance $(g s)$ was daily examined, using portable LI-6400 XT (LI-COR, USA), until gs values were lower than $0.2 \mathrm{mmol} \mathrm{H}_{2} \mathrm{O} \mathrm{m}^{-2} \mathrm{~s}^{-1}$ (Flexas, Bota, Loreto, Cornic, \& Sharkey, 2004). At this point, gas exchange parameters ( $A, C i, E$ and, gs) were assessed on the central leaflet of the third fully expanded trifoliate leaf (apex-base direction) inside the greenhouse at 9.00 a.m. Plant height was also measured at the start $(\mathrm{H} 1)$ and the end $(\mathrm{H} 2)$ of the WD period. The mean length of internodes corresponded to the ratio between $\mathrm{H} 1$ and $\mathrm{H} 2$ and the number of nodes. The relative growth rate in height (RGRH) was calculated according to Molinari et al. (2020). Total leaf area was measured using a leaf area meter (LI $3100 \mathrm{C})$. Leaf-blades, stems, petioles, and roots were dried in a forced aeration oven at $60^{\circ} \mathrm{C}$ to constant weight, so that shoot dry matter (leaf blades + stems + petioles), root dry matter (per plant), and total dry matter were weighed. Soil water potential (MPa) was determined in the WD group using a WP4C (Decagon) potential meter.

\section{Water deficit tolerance test, daily transpiration, and statistical analysis}

Seeds from soybean GM lines and BRS 283 cultivar were grown and transferred to $1 \mathrm{~L}$ pots as described above. The experiment was carried out with 20 replicates in a randomized complete block design. At the $\mathrm{V} 2$ developmental stage, irrigation was withheld for 19 days, and during this period, daily transpiration (g day ${ }^{-1}$ ) was assessed by the loss of water between consecutive days through the daily weighing of pots. After that, all plants were re-hydrated until they presented a plain recovery (eight days). Following this period, the green leaf area $\left(\mathrm{dm}^{2}\right)$, assessed at the third trifoliate of treated plants was measured, using the equipment LI-3100C. The dry mass of the different tissues was also analyzed. Growth, physiological, and agronomic parameters were analyzed by ANOVA and the mean comparisons were carried out by the Tukey test ( $p \leq 0.05)$. Molecular analyses were performed by REST software (Pfaffl, Horgan, \& Dempfle, 2002).

\section{RESULTS AND DISCUSSION}

Some studies indicate that the overexpression of DREB2A proteins is effective in increasing abiotic stresses tolerance in plants (Mizoi et al. 2013, Sadhukhan et al., 
2014). In our study, increased expression levels of GmDREB2A;2 genes in soybean $\mathrm{GM}$ events confirm the activation of GIDREB2A;2 cisgene driven by 35SCaMV promoter. Highlighting differences in gene expression triggered by water treatments in C conditions in VEG and REP developmental stages, cisgene expression was significantly high for all three events, with the highest levels of expression being detected for GmDREB2A;2 FL event (Figures 1A and 1B). In WD conditions, cisgene expression levels were lower, which may be in part attributed to endogenous GmDREB2A;2 gene expression in conventional cultivar BRS 283 triggered by the imposed treatment.

Expression levels of LEA proteins in GM plants indicate that TF GmDREB2A;2 induced expression of these proteins under WD conditions (Figures $1 C$ and $1 D$ ). In the VEG period, the LEA6 expression level was higher for all three GM events, while in the REP period, GmDREB2A;2 CA-1 and GmDREB2A;2 FL presented higher expression levels (Figure $1 C$ ). For the $L E A 2$ gene, higher expression levels were identified for GmDRE2A;2 CA-1 and GmDREB2A;2 FL events under WD imposed in both VEG and REP periods (Figure 1D). LEA2 and LEA6 are Dehydrins (DHNs) proteins that accumulate in response to abiotic stresses (Battaglia, Olvera-Carrillo, Garciarrubio, Campos, \& Covarrubias, 2008). Koag, Wilkens, Fenton, Resnik, Vo and Close (2009) have identified that the interaction of such proteins with lipids in the membrane or with partially denatured proteins helps protect cells against damage caused by low water potential. Previous studies evaluated the expression level of dehydrin in response to abiotic stresses and showed increased levels in response to osmotic stress (Chiappetta et al., 2015), ABA, salicylic acid, and methyl jasmonate application, and drought, cold and, heat stresses in grapevine (Yang et al. 2012). Specifically, in soybean GM with different transcriptional factors, higher expression levels of LEA2 and LEA6 genes under WD were identified (Honna et al., 2016; Fuganti-Pagliarini et al., 2017; Molinari et al., 2020), corroborating the results obtained in the current study.

Considering the heat shock protein gene $H S P 70$, higher expression levels were detected under WD in the VEG period for GmDREB2A;2 CA-1 and GmDREB2A;2 FL GM events. A similar expression profile was observed for GM events and BRS 283 under WD imposed in the REP period, but with relatively lower expression levels (Figure 1E). This result indicated that the development period has interfered in the responses for HSPs mediated by the different gene constructs. In Arabidopsis, the overexpression of TF DREB2ACA also activated genes induced by thermal stress under WD (Sakuma et al., 2006a; Sakuma et al., 2006b). Specifically, for HSP70, overexpression of GmDREB2A;2 FL and GmDREB2A;2 CA, resulted in lower activation and increase of $H S P 70$ transcripts level, respectively (Mizoi et al., 2013).

When seedling growth was assayed, BRS 283 showed a GRR (growth reduction rate) of $90 \%$ on the total length of seedings, in response to osmotic stress, followed by GmDREB2A;2 CA-1 (70\%), GmDREB2A;2 CA-2 (65\%), and GmDREB2A;2 FL (60\%) GM events. For root growth, conventional cultivar BRS 283 and GmDREB2A;2 CA-1 $\mathrm{GM}$ event presented greater reductions of growth when compared to other lines, $80 \%$, and $65 \%$, respectively. However, the hypocotyl growth rate was not impaired as no significant difference was identified when genotypes were compared. These results suggested that the insertion of TFs GmDREB2A;2 FL and GMDREB2A;2 CA, when compared to the background genotype, did not seriously reduce root and seedling length which are considered, respectively, a sensitive parameter to differentiate physiological quality and to identify more adapted genotypes (Vieira et al., 2013). For growth data, genotype (Table 1) effects were observed for all variables analyzed, with GmDREB2A;2 CA-1 events showing inferior development 
about the other genotypes. The overexpression of DREB2ACA in Arabidopsis also induced growth disturbances (Sakuma et al. 2006a) and germination in seedlings (Mizoi et al., 2013).

Physiological data assayed showed that WD imposition resulted in an accentuated reduction of gas exchange parameters for all analyzes genotypes. BRS 283 , however, showed a more notable decline. Data from the photosynthetic rate of GM lines nevertheless indicated a better physiological performance under water restriction (Table 2 ). These results are consistent with an earlier study that also observed a decrease in gas exchange parameters under lack of water (Quain et al., 2014). The conventional cultivar, despite lower photosynthetic rate also showed higher $\mathrm{CO}_{2}$ accumulation, probably due to reduced $\mathrm{CO}_{2}$ utilization in the photosynthesis process (Mutava et al., 2015), which impaired tolerance, reflecting in a lower green area (Figure 2).
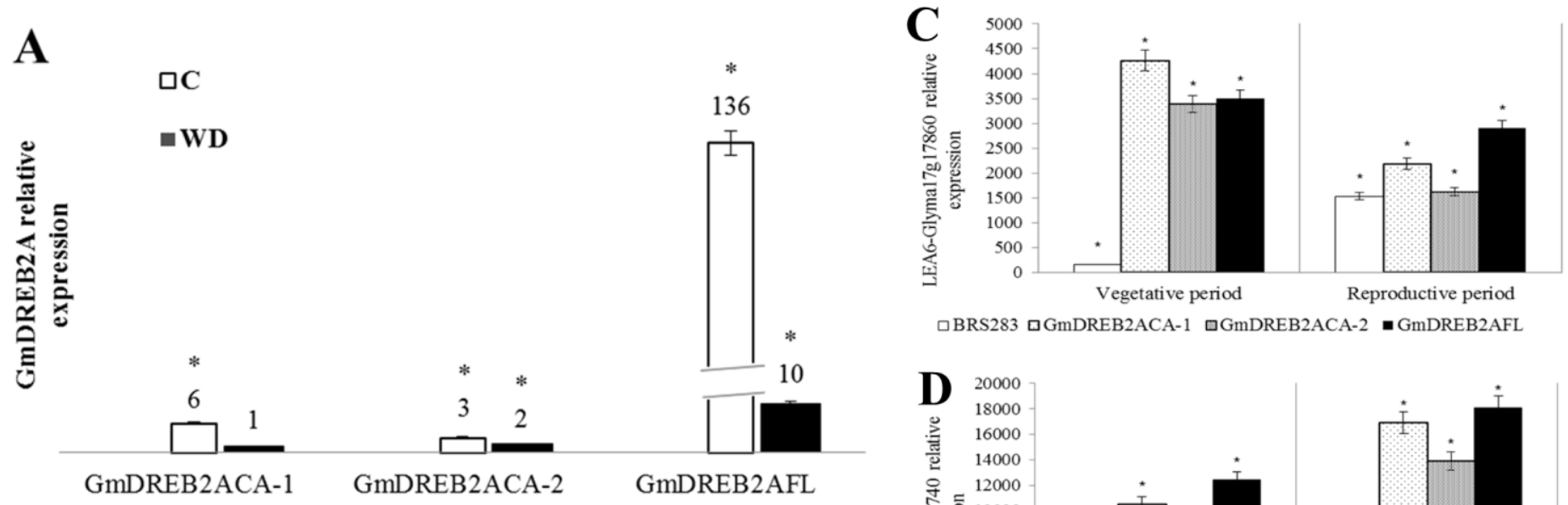

$\square$ BRS283 घGmDREB2ACA-1 aGmDREB2ACA-2 -GmDREB2AFL

B



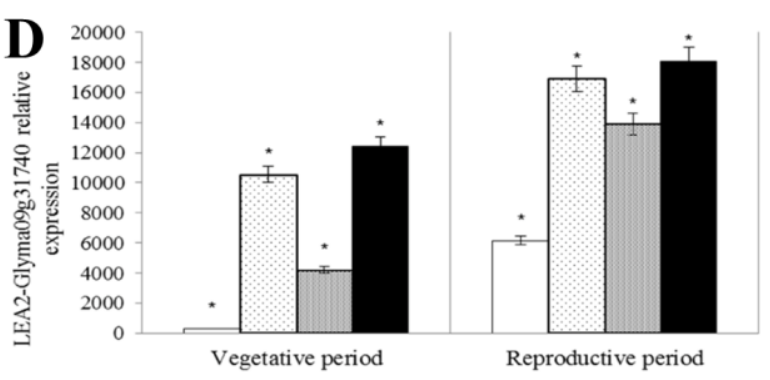

$\square$ BRS283 $\square$ GmDREB2ACA-1 GGmDREB2ACA-2 @ GmDREB2AFL
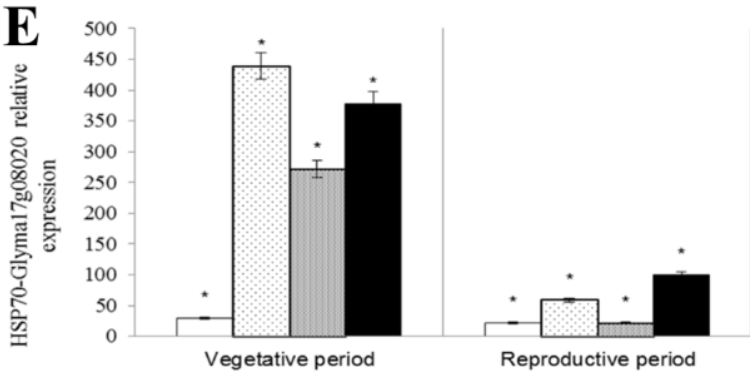

口BR283 aGmDREB2ACA-1 aGmDREB2ACA-2 -GmDREB2AFL

Figure 1. Gene expression analyses: Cisgene GmDREB2A;2 and drought-inducible genes expression levels in GM events GmDREB2A;2 FL, GmDREB2A;2 CA-1, GmDREB2A;2 CA-2 under control (C) and WD (water deficit) treatment conditions in VEG (A) and REP (B) developmental periods. Expression values under $C$ were calibrated with the expression of BRS 283 cultivar under the same condition; and expression values under WD treatment were calibrated with the expression of BRS 283 cultivar under the same condition. Gene expression analyses of $L E A 6$, LEA2 and $H S P 7 O$ in C, D and E, respectively, under WD conditions in VEG and REP developmental periods. The expression was calibrated with samples in the control condition. Significantly differences between BRS 283 and GM plants were assayed using REST 2009 software. (* significant at $p \leq 0.05$ ) software, biological replicates $n=6$. 
Table 1. Growth parameters of soybean plants genetically modified with GmDREB2A;2 FL and GmDREB2A;2 CA, and conventional cultivar BRS 283. No significant interaction between C and WD conditions was identified. Data compare the main genotype effect and represent the average of the genotypes under both water conditions.

\begin{tabular}{|c|c|c|c|c|c|c|c|c|c|}
\hline Genotype & $\operatorname{LDM}(\mathrm{g})$ & PDM (g) & RDM (g) & TDM (g) & $\mathbf{F A}\left(\mathrm{cm}^{2}\right)$ & RGR (\%) & GLDM (g) & GFA $\left(\mathrm{cm}^{2}\right)$ & RDM (g) \\
\hline BRS 283 & $0.71 \pm 0.02 \mathrm{a}$ & $0.58 \pm 0.02 \mathrm{a}$ & $1.04 \pm 0.09 \mathrm{a}$ & $2.34 \pm 0.10 \mathrm{a}$ & $258.76 \pm 6.02 \mathrm{a}$ & $13.12 \pm 1.39 \mathrm{~b}$ & $0.24 \pm 0.04 c$ & $60.33 \pm 10.78 \mathrm{c}$ & $0.82 \pm 0.02 \mathrm{ab}$ \\
\hline GmDREB2A;2 CA-1 & $0.55 \pm 0.03 b$ & $0.46 \pm 0.07 b$ & $0.87 \pm 0.07 \mathrm{~b}$ & $1.87 \pm 0.09 \mathrm{~b}$ & $226.10 \pm 7.88 b$ & $20.38 \pm 1.64 a$ & $0.49 \pm 0.05 \mathrm{~b}$ & $124.51=13.00 \mathrm{~b}$ & $0.86 \pm 0.02 \mathrm{ab}$ \\
\hline GmDREB2A;2 CA-2 & $0.64 \pm 0.02 \mathrm{a}$ & $0.54 \pm 0.02 \mathrm{a}$ & $0.99 \pm 0.09 \mathrm{ab}$ & $2.17 \pm 0.01 \mathrm{a}$ & $244.52 \pm 6.15 \mathrm{ab}$ & $23.24 \pm 1.59 \mathrm{a}$ & $0.52 \pm 0.05 b$ & $123.54 \pm 12.58 b$ & $0.81 \pm 0.02 b$ \\
\hline GmDREB2A;2 FL & $0.64 \pm 0.01 \mathrm{a}$ & $0.54 \pm 0.02 \mathrm{a}$ & $0.97 \pm 0.07 \mathrm{ab}$ & $2.15 \pm 0.08 \mathrm{a}$ & $252.44 \pm 5.67 \mathrm{a}$ & $20.47 \pm 1.43 \mathrm{a}$ & $0.87 \pm 0.07 \mathrm{a}$ & $197.97 \pm 15.00 \mathrm{a}$ & $0.88 \pm 0.02 \mathrm{a}$ \\
\hline CV $(\%)$ & 13.91 & 11.59 & 14.56 & 10.30 & 9.51 & 35.67 & 42.94 & 45.73 & 10.15 \\
\hline
\end{tabular}

$C=$ control; $W D=$ water deficit; $L D M=$ leaves dry matter; $P D M=$ petiole dry matter; $R D M=$ roots dry matter; TDM= total dry matter; $F A=$ foliar area. Means $(n=9) \pm$ standard error followed by the same letters do not differ by the Tukey test $(p \leq 0.05)$; RGR= relative growth rate; GLDM= green leaves dry matter; $G F A=$ green foliar area; $C V=$ coefficient of variance. Means $(n=20) \pm$ standard error followed by the same letters do not differ by the Tukey test $(p \leq 0.05)$.

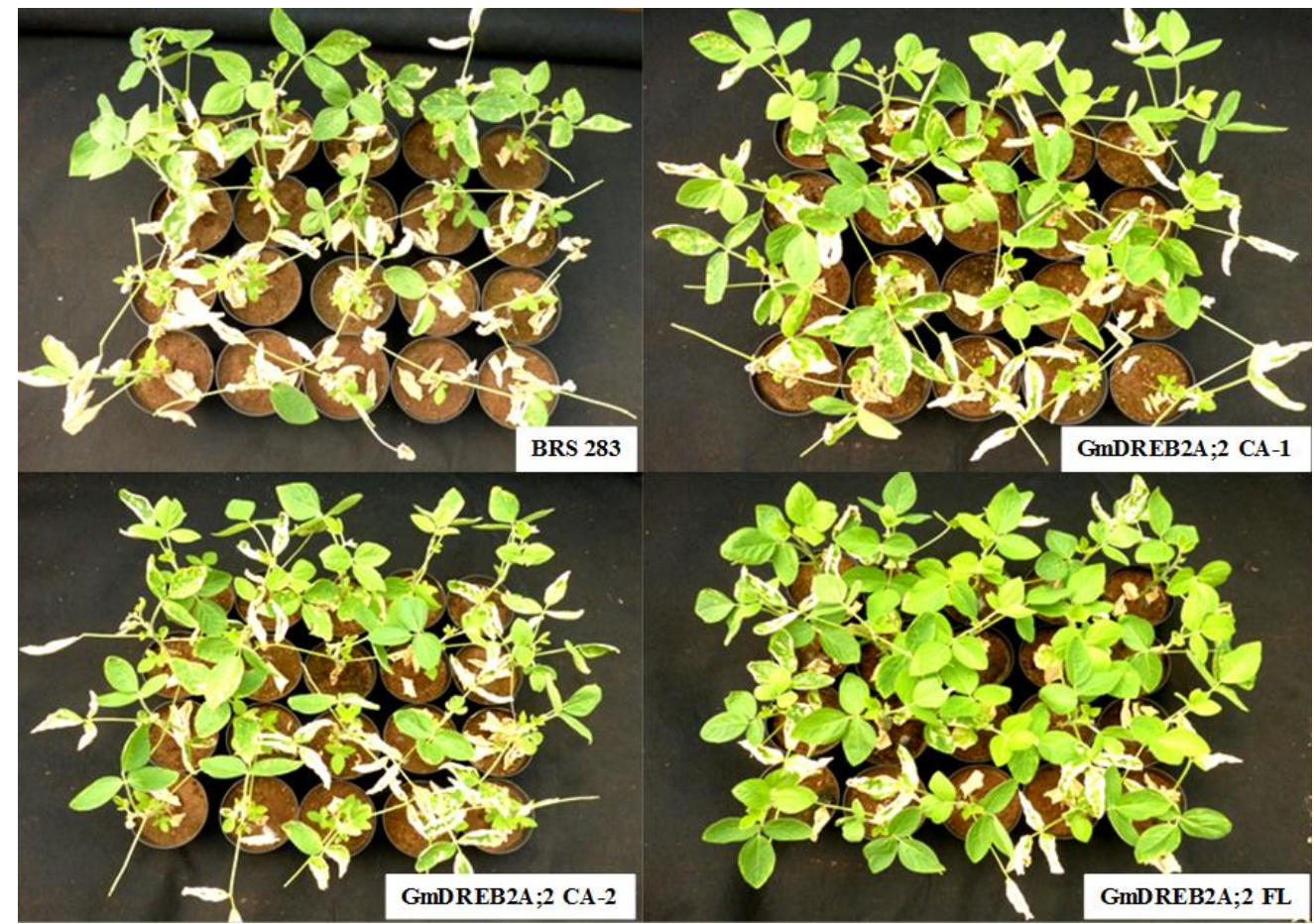

Figure 2. Water deficit tolerance experiment carried out with soybean genetically modified plants GmDREB2A;2 FL and GmDREB2A;2 CA and conventional cultivar BRS 283. The photo was recorded 19 days after water restriction followed by eight days of re-irrigation, time required for plants to present an evident recovery from water deficit treatment.

Differences between soybean GM events and BRS 283 were observed for RGR (relative growth rate), GLDM (green leaves dry matter), GFA (green foliar area), and RDM (roots dry matter) (Table 1), with BRS 283 presenting inferior performance when compared to GM events. GmDREB2A;2 FL event showed higher GFA values when compared to other events after 19 days of withheld irrigation followed by eight days of rehydration (Figure 2). Daily transpiration data revealed that at the beginning of the WD experiment, cultivar BRS 283 showed transpiration about the GM events (Figure $3 \mathrm{~A}$ ), but by the end of the experimental period (Figure $3 \mathrm{~B}$ ) it 
presented a better water status in the substrate. For GM event GmDREB2A;2 CA-1, this response could be a consequence of the plant's smaller size (Figure 2). According to Tuberosa (2012), a water conservation mechanism could be considered advantageous for long periods of water restriction since this reservoir in the soil can be made accessible for use in future periods.
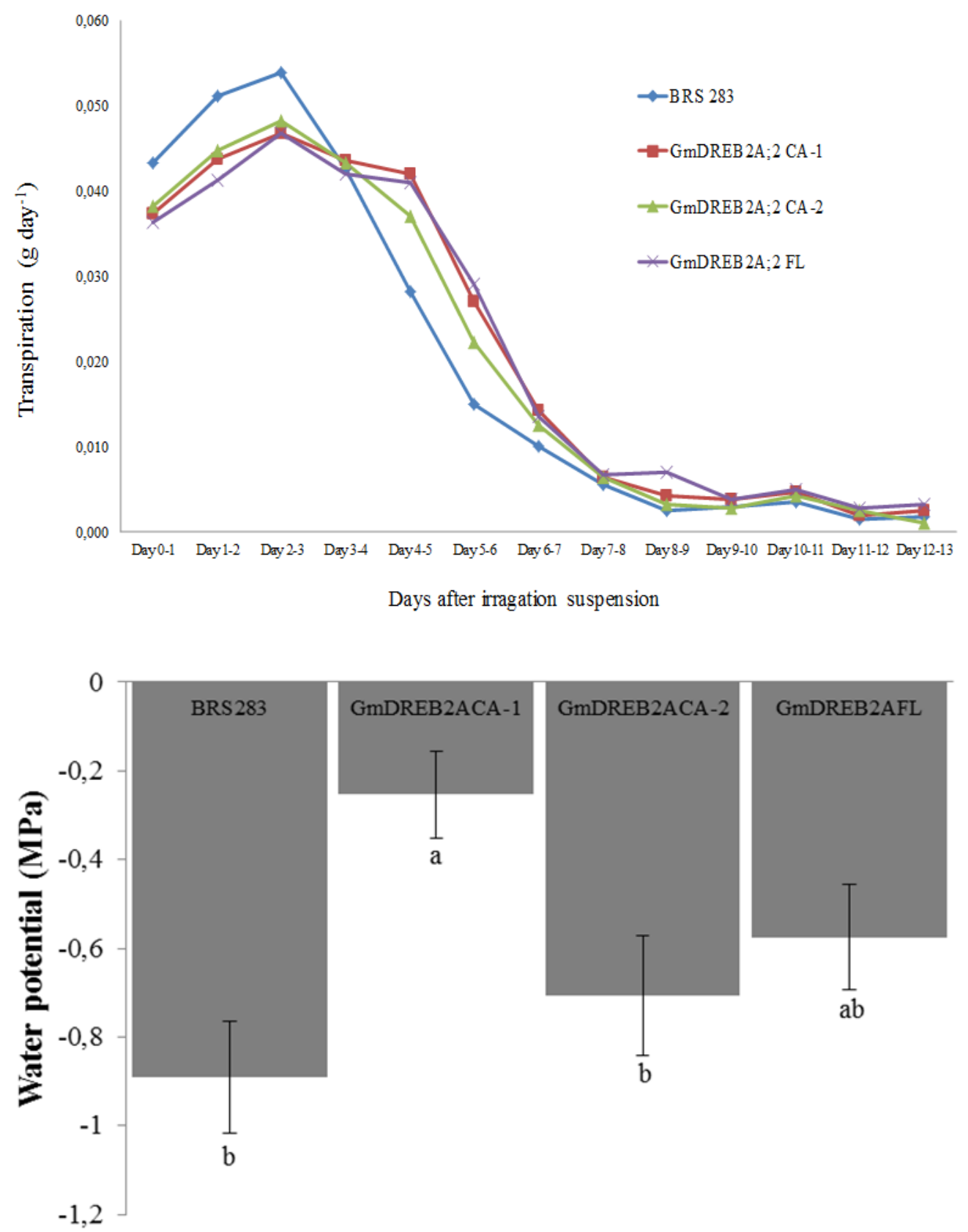

Figure 3. In $A$, daily transpiration of soybean genetically modified plants GmDREB2A;2 FL and GmDREB2A;2 CA, and conventional cultivar, BRS 283, under water deficit treatment. Values represent means $(n=20)$. In $B$, substrate water potential of soybean genetically modified plants, and conventional cultivar, BRS 283, under WD treatment. Means values ( $n=9)$ and standard error, represented by columns and bars respectively, followed by similar uppercase letters (between water conditions) and lowercase letters (among genotypes) do not differ by Tukey test ( $p \leq 0.05$ ). 
Table 2. Physiological parameters of soybean plants genetically modified with GmDREB2A;2 FL and GmDREB2A;2 CA and conventional cultivar BRS 283.

\begin{tabular}{|c|c|c|c|c|c|c|c|c|c|c|}
\hline \multicolumn{6}{|c|}{$\mathrm{g}_{\mathrm{s}}\left(\mathrm{mmol} \mathrm{H}_{2} \mathrm{O} \mathrm{m}^{-2} \mathrm{~s}^{-1}\right)$} & \multicolumn{5}{|c|}{$\mathrm{Ci}\left(\mu \mathrm{mol} \mathrm{CO} \mathrm{Col}^{-1}\right)$} \\
\hline & BRS 283 & $\begin{array}{c}\text { GmDREB2A;2 } \\
\text { CA-1 }\end{array}$ & $\begin{array}{c}\text { GmDREB2A;2 } \\
\text { CA-2 }\end{array}$ & $\begin{array}{c}\text { GmDREB2A;2 } \\
\text { FL }\end{array}$ & MEAN WC & BRS 283 & $\begin{array}{c}\text { GmDREB2A;2 } \\
\text { CA-1 }\end{array}$ & $\begin{array}{c}\text { GmDREB2A;2 } \\
\text { CA-2 }\end{array}$ & $\begin{array}{c}\text { GmDREB2A; } \\
2 \mathrm{FL}\end{array}$ & MEAN WC \\
\hline C & $0.48 \pm 0.02$ & $0.47 \pm 0.02$ & $0.44 \pm 0.02$ & $0.47 \pm 0.03$ & $0.46 \pm 0.01 \mathrm{~A}$ & $287.16 \pm 4.09$ & $290.44 \pm 3.42$ & $285.13 \pm 5.23$ & $291.86 \pm 2.85$ & $288.65 \pm 1.96 \mathrm{~A}$ \\
\hline wD & $0.02 \pm 0.00$ & $0.08 \pm 0.02$ & $0.04 \pm 0.01$ & $0.04 \pm 0.01$ & $0.05 \pm 0.01 \mathrm{~B}$ & $257.9 \pm 16.38$ & $194.36 \pm 22.34$ & $202.03 \pm 18.45$ & $216.83 \pm 23.30$ & $217.78=10.56 \mathrm{~B}$ \\
\hline \multicolumn{6}{|c|}{$\mathrm{A}\left(\mu \mathrm{mol} \mathrm{CO} 2 \mathrm{~m}^{-2} \mathrm{~s}^{-1}\right)$} & \multicolumn{5}{|c|}{$\mathbf{E}\left(\mathbf{m m o l ~ H} \mathrm{H}_{2} \mathrm{O} \mathrm{m}^{-2} \mathrm{~s}^{-1}\right)$} \\
\hline & BRS 283 & $\begin{array}{c}\text { GmDREB2A;2 } \\
\text { CA-1 }\end{array}$ & $\begin{array}{c}\text { GmDREB2A;2 } \\
\text { CA-2 }\end{array}$ & $\begin{array}{c}\text { GmDREB2A;2 } \\
\text { FL }\end{array}$ & MEAN WC & BRS 283 & $\begin{array}{c}\text { GmDREB2A;2 } \\
\text { CA-1 }\end{array}$ & $\begin{array}{c}\text { GmDREB2A;2 } \\
\text { CA-2 }\end{array}$ & $\begin{array}{c}\text { GmDREB2A; } \\
2 \mathrm{FL}\end{array}$ & MEAN WC \\
\hline C & $21.94 \pm 0.86 \mathrm{Aa}$ & $21.69 \pm 0.80 \mathrm{Aa}$ & $20.56 \pm 0.70 \mathrm{Aa}$ & $21.30 \pm 0.46 \mathrm{Aa}$ & $21.37 \pm 0.36 \mathrm{~A}$ & $5.87 \pm 0.17$ & $5.88 \pm 0.14$ & $5.43 \pm 0.27$ & $5.82 \pm 0.16$ & $5.75 \pm 0.10 \mathrm{~A}$ \\
\hline WD & $1.38 \pm 0.60 \mathrm{Bb}$ & $5.52 \pm 0.63 \mathrm{Ba}$ & $4.65 \pm 0.22 \mathrm{Ba}$ & $4.01 \pm 1.27 \mathrm{Bab}$ & $3.89 \pm 0.54 \mathrm{~B}$ & $0.68 \pm 0.09$ & $0.97 \pm 0.08$ & $1.16 \pm 0.17$ & $1.04 \pm 0.18$ & $0.96 \pm 0.07 \mathrm{~B}$ \\
\hline
\end{tabular}

$\mathrm{C}=$ control; $\mathrm{WD}=$ water deficit; $\mathrm{LDM}=$ leaves dry matter; $\mathrm{PDM}=$ petiole dry matter; $\mathrm{RDM}=$ roots dry matter; $T D M=$ total dry matter; $F A=$ foliar area. Means $(n=9) \pm$ standard error followed by the same letters do not differ by the Tukey test $(p \leq 0.05)$; RGR= relative growth rate; GLDM= green leaves dry matter; GFA= green foliar area; $C V=$ coefficient of variance. Means $(n=20) \pm$ standard error followed by the same letters do not differ by the Tukey test $(p \leq 0.05)$.

For the yield components, in the VEG and REP stages, no genotype and water condition effects were observed. Average and standard error identified for these parameters in the VEG stage were $11.97 \pm 5.75$ for TNP; $47.50 \pm 2.48 \mathrm{~g}$ for TPDM; $243.91 \pm 13.29$ for TNS; and $34.07 \pm 1.54 \mathrm{~g}$ for TSDM. Soybean plants submitted to water restriction for short periods during the VEG period usually recover without any damage to yield. These authors showed that soybean plant heights and leaf areas exhibited rapid increases and partial compensation for their decreased sizes, after rehydration. This compensation effect was dependent on drought level, plant growth stage, duration, and frequency, but enough to avoid yield losses (Dong et al. 2019). However, when water shortage is imposed for longer periods, it may affect not only photosynthesis, as observed in the present study (Table 2), but also height and leaf area index (Chavarria, Durigon, Klein, \& Kleber, 2015).

In the REP developmental period, average and standard error identified for TNP and TNS parameters for all genotypes and water conditions were $99.04 \pm 8.77$ and 218.04 \pm 20.61 . Although not statically different, GmDREB2A;2 FL presented higher values of TPDM and TSDM, 36.09 $\pm 2.46 \mathrm{~g}$ and $52.21 \pm 3.74 \mathrm{~g}$, respectively, which corroborated data from the WD tolerance test and also indicated this GM event as the one with the better performance under treatment. It suggests that it is possible to obtain soybean lines GM with TF GmDREB2A;2 with minor losses in final yields, an important trait for a grain crop, such as soybean. GmDREB2A;2 CA-1 event presented lower values for TPDM and TSDM $(30.98 \pm 2.36 \mathrm{~g}$ and $43.46 \pm 3.33 \mathrm{~g}$, respectively) compared to the other $\mathrm{GM}$ events, related to the lower growth observed for this event (Table 1).

It is important to highlight that the greater performance of $\mathrm{GM}$ lines during germination, emergence, and VEG stage would reflect in a better plant establishment, which in turn would result in improved, or fewer losses in final yield in many soybean production regions in Brazil. Additionally, important metabolic changes in these same GM events were reported in a prior study, where the main 
metabolic defense strategy was the synthesis of metabolites associated with carbohydrates metabolism, in leaves under treatment conditions. In roots, increased levels of $\beta$-glucose, asparagine, and phenylalanine were found in GmDREB2A; 2 FL and GmDREB2A; 2 CA-1 events, suggesting that these metabolites could act as osmoprotectants improving drought responses (Marinho et al., 2019).

\section{CONCLUSIONS}

In the current study, the overexpression of TFs GmDREB2A;2 FL and GmDREB2A;2 CA in soybean triggered the expression of WD-induced genes, under treatment imposed in both the VEG and REP developmental periods. Seedlings from soybean plants GM with TFs GmDREB2A;2 FL and GmDREB2A;2 CA kept growth in osmotic treatment during germination and also showed a better performance for physiological and growth parameters under WD during the VEG period, suggesting an improved tolerance to drought. Therefore, the observed molecular and physiological responses and the variation in metabolites profile identified for these different genotypes in our previous study may explicate the better performance of genetically modified soybean plants and the greater sensitivity of the BRS 283 to WD. Additional experiments in field conditions may allow further characterization of these lines, adding information on their responses under water limiting conditions, in real crop cultivation circumstances.

Finally, in the case of Brazil, the cultivation of these drought-tolerant lines throughout the national territory, which has a wide range of climatic conditions, can help to minimize productivity and financial losses due to periods of water deficit. Producers in general, from small family farms to large producing companies, consider soybean as a good crop option for some reasons such as good profit, ease of negotiation and marketing, and the existence of credit to finance production, therefore, offering these producers an option to reduce losses in dry seasons can really impact the local and national economy.

\section{ACKNOWLEDGMENTS}

The authors would like to thank CAPES (Coordination for the Improvement of Higher Education Personnel) and CNPq (Brazilian National Council for Scientific and Technological Development) for granting scholarships to some of the authors; Science and Technology Research Partnership for Sustainable Development (SATREPS) of the JST, JICA and by the Embrapa for financial support.

\section{REFERENCES}

Battaglia, M., Olvera-Carrillo, Y., Garciarrubio, A., Campos, F., \& Covarrubias, A. A. (2008). The enigmatic LEA proteins and other hydrophilins. Plant Physiology, 148(1), 6-24. https://doi.org/10.1104/pp.108.120725

Chavarria, G., Durigon, M. R., Klein, V. A., \& Kleber, H. (2015). Photosynthetic restriction of soybean plants under variation of water availability. Ciência Rural, 45(8), 1387-1393. http://dx.doi.org/10.1590/0103-8478cr20140705

Chiappetta, A., Muto, A., Bruno, L., Woloszynska, M., Van Lijsebettens, M., \& Bitonti, M. B. (2015). A dehydrin gene isolated from feral olive enhances drought tolerance in Arabidopsis transgenic plants. Frontiers in Plant Science, 6(392), 1-15. https://doi.org/10.3389/fpls.2015.00392 
Dong, S., Jiang, Y., Dong, Y., Wang, L., Wang, W., Ma, Z., Yan, C., Ma, C., \& Liu, L. (2019). A study on soybean responses to drought stress and rehydration. Saudi Journal of Biological Sciences, 26 (8), 2006-2017. https://doi.org/10.1016/j.sjbs.2019.08.005

Dubouzet, J. G., Sakuma, Y., Ito, Y., Kasuga, M., Dubouzet, E. G., Miura, S., ... \& Yamaguchi-Shinozaki, K. (2003). OsDREB genes in rice, Oryza sativa L., encode transcription activators that function in drought-, high-salt- and cold-responsive gene expression. The Plant Journal, 33(4), 751-763. https://doi.org/10.1046/j.1365-313X.2003.01661.x

Flexas, J., Bota, J., Loreto, F., Cornic, G., \& Sharkey, T. D. (2004). Diffusive and metabolic limitations to photosynthesis under drought and salinity in C3 plants. Plant Biology, 6(03), 269-279. https://doi.org/10.1055/s-2004-820867

Fuganti-Pagliarini, R., Ferreira, L. C., Rodrigues, F. A., Molinari, H. B., Marin, S. R., Molinari, M. D., ... \& Nepomuceno, A. L. (2017). Characterization of soybean genetically modified for drought tolerance in field conditions. Frontiers in Plant Science, 8(448), 1-15. https://doi.org/10.3389/fpls.2017.00448

Guo, J., \& Wang, M. H. (2011). Expression profiling of the DREB2 type gene from tomato (Solanum lycopersicum L.) under various abiotic stresses. Horticulture, Environment, and Biotechnology, 52(1), 105-111. https://doi.org/10.1007/s13580-011-0125-5

Honna, P. T., Fuganti-Pagliarini, R., Ferreira, L. C., Molinari, M. D., Marin, S. R., de Oliveira, M. C., ... \& Nepomuceno, A. L. (2016). Molecular, physiological, and agronomical characterization, in greenhouse and in field conditions, of soybean plants genetically modified with AtGolS2 gene for drought tolerance. Molecular Breeding, 36(11), 1-17. https://doi.org/10.1007/s11032016-0570-z

Koag, M. C., Wilkens, S., Fenton, R. D., Resnik, J., Vo, E., \& Close, T. J. (2009). The Ksegment of maize DHN1 mediates binding to anionic phospholipid vesicles and concomitant structural changes. Plant Physiology, 150(3), 1503-1514. https://doi.org/10.1104/pp.109.136697

Livak, K. J., \& Schmittgen, T. D. (2001). Analysis of relative gene expression data using real-time quantitative PCR and the 2- $\triangle \Delta C T$ method. Methods, 25(4), 402-408. https://doi.org/10.1006/meth.2001.1262

Lopes, M. A., Faleiro, F. G., Ferreira, M. E., Lopes, D. B., Vivian, R., \& Boiteux, L. S. (2012). Contribuição da Embrapa na produção de novas cultivares de plantas e seu impacto na agricultura. Crop Breeding and Applied Biotechnology, 12, 3146. https://doi.org/10.1590/S1984-70332012000500005

Marcolino-Gomes, J., Rodrigues, F. A., Fuganti-Pagliarini, R., Nakayama, T. J., Ribeiro Reis, R., Bouças Farias, J. R., ... \& Nepomuceno, A. (2015). Transcriptome-wide identification of reference genes for expression analysis of soybean responses to drought stress along the day. PLOS ONE, 10(9), e0139051. https://doi.org/10.1371/journal.pone.0139051 
Marinho, J. P., Coutinho, I. D., Lameiro, R. F., Marin, S. R. R., Colnago, L. A., Nakashima, K., ... \& Mertz-Henning, L. M. (2019). Metabolic alterations in conventional and genetically modified soybean plants with GmDREB2A; $2 \mathrm{FL}$ and GmDREB2A; 2 CA transcription factors during water deficit. Plant Physiology and Biochemistry, 140, 122-135. https://doi.org/10.1016/j. plaphy.2019.04.040

Mizoi, J., Ohori, T., Moriwaki, T., Kidokoro, S., Todaka, D., Maruyama, K., ... \& Yamaguchi-Shinozaki, K. (2013). GmDREB2A; 2, a canonical DEHYDRATIONRESPONSIVE ELEMENT-BINDING PROTEIN2-type transcription factor in soybean, is posttranslationally regulated and mediates dehydration-responsive element-dependent gene expression. Plant Physiology, 161(1), 346-361. https://doi.org/10.1104/pp.112.204875

Molinari, M. D. C., Fuganti-Pagliarini, R., Barbosa, D. A., Andreatta, E. C., Nepomuceno, A. L., \& Hertz-Henning, L. M. (2018). Seleção de sementes de soja geneticamente modificadas com o gene marcador bar por meio do teste de germinação em solução de glufosinato de amônio. Revista de Ciências Agrárias - Amazonian Journal of Agricultural and Environmental Sciences, 61, 1-17. http://dx.doi.org/10.22491/rca.2018.2883

Molinari, M. D. C., Fuganti-Pagliarini, R., Marin, S. R. R., Ferreira, L. C., Barbosa, D. D. A., Marcolino-Gomes, J., ... \& Nepomuceno, A. L. (2020). Overexpression of AtNCED3 gene improved drought tolerance in soybean in greenhouse and field conditions. Genetics and Molecular Biology, 43(3), 1-12. https://doi.org/10.1590/1678-4685-GMB-2019-0292

Mutava, R. N., Prince, S. J. K., Syed, N. H., Song, L., Valliyodan, B., Chen, W., \& Nguyen, H. T. (2015). Understanding abiotic stress tolerance mechanisms in soybean: A comparative evaluation of soybean response to drought and flooding stress. Plant Physiology and Biochemistry, 86, 109-120. https://doi.org/10.1016/j.plaphy.2014.11.010

Paz, M. M., Martinez, J. C., Kalvig, A. B., Fonger, T. M., \& Wang, K. (2006). Improved cotyledonary node method using an alternative explant derived from mature seed for efficient Agrobacterium-mediated soybean transformation. Plant Cell Reports, 25(3), 206-213. https://doi.org/10.1007/s00299-005-0048-7

Pfaffl, M. W., Horgan, G. W., \& Dempfle, L. (2002). Relative expression software tool (RESTC) for group-wise comparison and statistical analysis of relative expression results in real-time PCR. Nucleic Acids Research, 30(9), e36-e36. https://doi.org/10.1093/nar/30.9.e36

Qin, F., Kakimoto, M., Sakuma, Y., Maruyama, K., Osakabe, Y., Tran, L. S. P., ... \& Yamaguchi-Shinozaki, K. (2007). Regulation and functional analysis of ZmDREB2A in response to drought and heat stresses in Zea mays L. The Plant Journal, 50(1), 54-69. https://doi.org/10.1111/j.1365-313X.2007.03034.x 
Quain, M. D., Makgopa, M. E., Márquez-García, B., Comadira, G., Fernandez-Garcia, N., Olmos, E., ... \& Foyer, C. H. (2014). Ectopic phytocystatin expression leads to enhanced drought stress tolerance in soybean (Glycine max) and Arabidopsis thaliana through effects on strigolactone pathways and can also result in improved seed traits. Plant Biotechnology Journal, 12(7), 903-913. https://doi.org/10.1111/pbi.12193

Sadhukhan, A., Kobayashi, Y., Kobayashi, Y., Tokizawa, M., Yamamoto, Y. Y., luchi, S., ... \& Sahoo, L. (2014). VuDREB2A, a novel DREB2-type transcription factor in the drought-tolerant legume cowpea, mediates DRE-dependent expression of stress-responsive genes and confers enhanced drought resistance in transgenic Arabidopsis. Planta, 240(3), 645-664. https://doi.org/10.1007/s00425-0142111-5

Sakuma, Y., Maruyama, K., Osakabe, Y., Qin, F., Seki, M., Shinozaki, K., \& Yamaguchi-Shinozaki, K. (2006a). Functional analysis of an Arabidopsis transcription factor, DREB2A, involved in drought-responsive gene expression. The Plant Cell, 18(5), 1292-1309. https://doi.org/10.1105/tpc.105.035881

Sakuma, Y., Maruyama, K., Qin, F., Osakabe, Y., Shinozaki, K., \& YamaguchiShinozaki, K. (2006b). Dual function of an Arabidopsis transcription factor DREB2A in water-stress-responsive and heat-stress-responsive gene expression. Proceedings of the National Academy of Sciences, 103(49), 1882218827. https://doi.org/10.1073/pnas.0605639103

Terashima, A., \& Takumi, S. (2009). Allopolyploidization reduces alternative splicing efficiency for transcripts of the wheat DREB2 homolog, WDREB2. Genome, 52(1), 100-105. https://doi.org/10.1139/G08-101

Tuberosa, R. (2012). Phenotyping for drought tolerance of crops in the genomics era. Frontiers in Physiology, 3(347), 1-26.. https://doi.org/10.3389/fphys.2012.00347

Vieira, F. C. F., Santos Junior, C. D., Nogueira, A. P. O., Dias, A. C. C., Hamawaki, O. T., \& Bonetti, A. M. (2013). Physiological and biochemical aspects of soybean cultivars submitted to water deficit induced by PEG 6000. Bioscience Journal, 29(3), 543-552. http://www.seer.ufu.br/.../12495

Villela, F. A., \& Beckert, O. P. (2001). Potencial osmótico de soluções aquosas de polietileno glicol 8000. Revista Brasileira de Sementes, 23, 267-275. https://www.abrates.org.br/files/artigos/58984c51c1fcf3.05150811_artigo37. pdf

Yang, Y., He, M., Zhu, Z., Li, S., Xu, Y., Zhang, C., ... \& Wang, Y. (2012). Identification of the dehydrin gene family from grapevine species and analysis of their responsiveness to various forms of abiotic and biotic stress. BMC Plant Biology, 12(1), 1-17. https://doi.org/10.1186/1471-2229-12-140 